\title{
New guidelines from the American Heart Association on prevention of infective endocarditis: a shift in paradigms, albeit raising new questions relative to those with congenitally malformed hearts
}

Dear Editor,

I read with great interest your comments ${ }^{1}$ regarding the recent guidelines provided by the American Heart Association for the prevention of infective endocarditis. ${ }^{2}$ In this statement, experts representing the American Heart Association extensively analysed the literature on procedure-related bacteraemia and infective endocarditis, results of prophylactic studies in animals, and retrospective and prospective studies of the prevention of infective endocarditis. The committee stated that the risk of bacteraemia from routine daily activities is much higher than that resulting from a dental procedure. They pointed out that the absolute risk of infective endocarditis from a dental procedure is exceedingly rare, so the number of cases that could be prevented by antibiotic prophylaxis is similarly small. They also concluded that prophylaxis against infective endocarditis for dental procedures is reasonable only for patients with cardiac conditions associated with known higher risks. The committee, however, reported only data relative to antibiotic prophylaxis, and did not consider data relative to prophylaxis in the setting of percutaneous closure of defects in patients with congenitally malformed hearts. In particular, they did not consider that closure of a persistently patent arterial duct may provide an alternative means of preventing bacterial endoarteritis. ${ }^{3,4}$ Such percutaneous closure has proven to be safe and effective. ${ }^{5,6}$ Transcatheter occlusion also has a significant advantage over antibiotic prophylaxis, since it could nullify over a lifetime the risk produced by bacteraemia due not only to dental procedures but also from routine daily activities. If antibiotic prophylaxis is not indicated in such patients, would prophylaxis produced by percutaneous closure be worthwhile? Or, if antibiotic prophylaxis is not indicated in patients with a persistently patent arterial duct, would percutaneous closure itself be contra-indicated? I am anxious to learn the opinion of the Editor-in-Chief regarding this issue?

Gianfranco Butera Pediatric Cardiology and GUCH Unit Policlinico San Donato IRCCS Italy

\section{References}

1. Baker E. A paradigm shift. Cardiol Young 2008; 18: 241-242.

2. Wilson W, Taubert KA, Gewitz M, et al. Prevention of infective endocarditis. Guidelines from the American Heart Association. Circulation 2007; 116: 1736-1754.

3. Sadiq M, Latif F, Ur-Rehman A. Analysis of infective endarteritis in patent ductus arteriosus. Am J Cardiol 2004; 93: 513-515.

4. Ozkoleki M, Ates M, Uslu N, Akcar M. Pulmonary and aortic valve endarteritis in an adult patient with silent ductus arteriosus. Jpn Heart J 2004; 45: 1057-1061.

5. Alwi M. PDA occlusion with the Amplatzer devices. In: Percutaneous interventions for Congenital Heart Disease. Sievert H, Qureshi SA, Wilson N, Hijazi ZM (eds). Informa Healthcare, London, 2007, pp 377-384.

6. Krishna Kumar R. Patent ductus arteriosus: coil occlusion. In: Percutaneous interventions for Congenital Heart Disease. Sievert $\mathrm{H}$, Qureshi SA, Wilson N, Hijazi ZM (eds). Informa Healthcare, London, 2007, pp 385-402.
Correspondence to: Dr Gianfranco Butera MD, PhD, Policlinico San Donato IRCCS, Via Morandi 30-20097 San Donato Milanese - Italy. Tel: +39252774328; Fax: +39252774459; E-mail: gianfranco.butera@grupposandonato.it 